\section{Homens adolescentes e vida sexual: heterogeneidades nas motivações que cercam a iniciação sexual}

\author{
Adolescent males and sex life: \\ heterogeneous motivations \\ related to sexual debut
}

\author{
${ }^{1}$ Escola de Enfermagem, \\ Universidade de São Paulo, \\ São Paulo, Brasil. \\ 2 Faculdade de Saúde \\ Pública, Universidade de São \\ Paulo, São Paulo, Brasil. \\ Correspondência \\ A. L. V. Borges \\ Departamento de \\ Enfermagem em Saúde \\ Coletiva, Escola de \\ Enfermagem, Universidade \\ de São Paulo. \\ Rua Dr. Enéas de Carvalho \\ Aguiar 419, \\ São Paulo, SP \\ 05403-000, Brasil. \\ alvilela@usp.br
}

\begin{abstract}
This article describes male adolescents' affective history and reasons for initiating or postponing sexual activity, using interviews with 184 males ages 15 to 19 and residing in the city of São Paulo, Brazil, in 2002. Factors for sexual debut included physical attraction, curiosity, and the desire to lose their virginity, suggesting a profile similar to the male social role. Most of the virgin adolescent males justified their choice based on issues of a romantic order, such as not having found the right person or because they preferred to remain virgin until marrying. The results showed a dual social pattern, valuing the feeling of love and deliverance to the loved one, simultaneously with the pressing physical and instinctive desire for sex. Traditional patterns of masculinity, like the dissociation between sex and love, appear to be transposed to sexual debut, revealing a diversity in the ways of experiencing sexuality during adolescence, related in turn to the sexual and reproductive health of men and their partners.
\end{abstract}

Sexual and Reproductive Health; Teen Health; Men's Health
Ana Luiza Vilela Borges 1

Néia Schor 2

\section{Introdução}

Um olhar mais aprofundado sobre a AIDS indica que há participação intensa de homens jovens na dinâmica da epidemia. Paradoxalmente, a despeito de tal fato, esse grupo encontra-se praticamente à margem de uma atenção adequada no âmbito do Sistema Único de Saúde (SUS). De um modo geral, verifica-se que as ações realizadas no nível da atenção básica voltam-se à distribuição esporádica de preservativos masculinos por unidades básicas de saúde, podendo-se afirmar que tal abordagem não considera, com propriedade, as questões que envolvem sua saúde sexual e reprodutiva. Dessa forma, faz-se necessário que a assistência à saúde dos homens jovens tenha como princípio que são atores com necessidades de saúde, sexualidade e reprodução a serem consideradas, tanto na suas relações com o outro, como em sua especificidade, conforme sugeriu Figueroa-Perea 1.

Coincidentemente à escassa presença dos homens jovens - principalmente os adolescentes - como foco das ações de atenção à saúde reprodutiva e sexual, observa-se que os estudos que tomam como referência tal grupo têm procurado conhecer e descrever práticas sexuais e comportamentais que possam agregar riscos de infecção ou transmissão do HIV. No entanto, as experiências afetivo-amorosas que, na maior parte das vezes, antecedem o início da vida sexual e ocorrem, pela primeira vez, na adolescência, 
como beijar, ficar e namorar, vêm sendo pouco abordadas e exploradas por estudiosos do campo da saúde coletiva.

Ao considerar que os adolescentes são majoritariamente solteiros, é necessário atribuir ao namoro maior atenção, pois, além de ser a relação afetiva mais comum e esperada do grupo etário, é nesse contexto que geralmente se dá o início da vida sexual 2 (nesta pesquisa, o início da vida sexual é tomado como sinônimo de primeira relação sexual). Borges 3 observou, por meio de uma investigação com adolescentes de 15 a 19 anos de idade, moradores de uma região periférica do Município de São Paulo, Brasil, que o namoro - anterior ou atual - foi associado positivamente à primeira relação sexual, mesmo considerando que nem todos os adolescentes, especialmente os homens, iniciaram a vida sexual em um relacionamento de namoro.

As questões referentes ao namoro são pouco exploradas por estudos conduzidos com populações adolescentes, e, é preciso lembrar, grandes inquéritos realizados no passado permitiram analisar o comportamento sexual e contraceptivo somente segundo o estado conjugal do adolescente esquecendo, contudo, que tanto o namoro quanto o ficar são contextos em que caminhos são abertos para a mútua exploração sexual. No cenário de aprofundamento da intimidade na adolescência, Schwartz 4 destacou que, muito antes da primeira relação sexual, a maior parte dos adolescentes já se engajou em experiências ditas pré-sexuais, como carícias e toques mais íntimos.

Aparentemente, pouco também tem sido investigado a respeito de homens que sequer iniciaram sua vida sexual, o que os torna praticamente ausentes dos estudos no campo da saúde sexual e reprodutiva, como se fossem assexuados ou estivessem indefinidamente à parte de contextos de vulnerabilidade que práticas sexuais inseguras possam trazer.

Por sua vez, a literatura tem mostrado que o início da vida sexual de homens ocorre basicamente ao redor dos 15 anos de idade 5,6,7,8, mediante diversos processos de organização e decisão quanto à vida sexual, advindos de diferentes concepções do significado e importância da iniciação sexual presentes no grupo em que ocorrem as relações sociais. Por exemplo, tomase o estudo de Bozon \& Heilborn ${ }^{9}$, que observaram, em homens entre 25 e 40 anos de idade de diferentes grupos sociais do Rio de Janeiro (1994 e 1995) e Paris (1993 e 1995), que "a primeira relação tem um caráter de prova, de experiência aventureira e arriscada" 9 (p. 130).

Por outro lado, Rieth 10 chamou a atenção para uma fase de transição em relação a antigos valores a respeito da iniciação sexual, revestida de contradições: a perda está conjugada a um ganho (perde-se a virgindade, porém ganha-se maturidade e amor da parceira), e os valores tradicionais estão conjugados aos modernos (os homens devem demonstrar seu desempenho sexual, porém muitos já passam também a relacionar a experiência sexual ao amor). Assim, no intuito de salientar as diferentes versões do desenvolvimento da sexualidade na adolescência entre os homens, a autora afirmou que a "experiência masculina (...) traduz-se em duas atitudes: $n u$ ma, o desempenho sexual é visto como um ganho, sustentando o poder da masculinidade, noutra, a atitude é decididamente romântica, em que o homem busca 'entregar-se' no momento certo e à parceira certa" 10 (p. 128).

Esses estudos evidenciaram que valores diferenciados - social, histórica e culturalmente construídos - são atribuídos à primeira relação sexual e norteiam o início da vida sexual de homens adolescentes que, por sua vez, exercem um papel preponderante na manutenção de tais valores no grupo social em que vivem e se relacionam. Toma-se como princípio que os homens têm motivações diferenciadas para o engajamento na vida sexual, e, aparentemente, essas motivações são fruto da construção de suas identidades masculinas baseada, entre outros, nas relações de gênero. Faz-se necessário refletir, contudo, que o modelo hegemônico de masculinidade deparara-se simultaneamente com um caráter plural e dinâmico de outras masculinidades, também reais.

Sendo o início da vida sexual um marco na vida reprodutiva de qualquer indivíduo e que ocorre com maior freqüência na adolescência, os aspectos que o antecedem e que advêm desse evento passam a ser importantes para conhecer, com mais profundidade, a trajetória afetivoamorosa e reprodutiva de homens adolescentes, possibilitando a elaboração de políticas de saúde sexual e reprodutiva voltadas a esse grupo e que entendam seu dinamismo e heterogeneidade.

Para tanto, este estudo parte de dois pressupostos. O primeiro é que os homens têm necessidades singulares, ou seja, não deveriam ser incorporados nos serviços de saúde apenas como coadjuvantes na atenção à saúde da mulher, ou seja, têm direitos sexuais e reprodutivos específicos a serem contemplados. O segundo é que a adolescência, em sua face social, não é um fenômeno homogêneo, o que nos leva a considerar que há diferentes adolescências moldadas por processos sociais distintos 11. Dessa forma, este trabalho propõe-se a descrever a trajetória afetivo-amorosa e as razões para o início ou o adiamento da vida sexual de adolescentes do sexo 
masculino entre 15 e 19 anos de idade, residentes na zona leste do Município de São Paulo.

\section{Procedimentos metodológicos}

Trata-se de estudo transversal desenvolvido em uma amostra representativa dos adolescentes de 15 a 19 anos de idade de ambos os sexos, moradores da área adscrita de uma unidade de saúde da família da zona leste do Município de São Paulo. A escolha de tal faixa etária justifica-se por compreender o período da adolescência em que a iniciação sexual ocorre com maior freqüência, mas ainda permite comparações, pois, nesse período, podem ser encontradas proporções razoáveis de indivíduos que ainda não tiveram relações sexuais.

Os sujeitos entrevistados foram selecionados por amostragem sistemática, com base em uma listagem obtida por meio do Sistema de Informação da Atenção Básica (SIAB) e ordenada por micro-área e pelo número das famílias cadastradas no Programa Saúde da Família que tinham, ao menos, um adolescente entre 15 e 19 anos de idade.

O tamanho amostral foi calculado baseandose na precisão desejada para se estimar a porcentagem de adolescentes de 15 a 19 que já tivessem iniciado a vida sexual, contemplando os objetivos do estudo maior no qual este trabalho está inserido 3,12. Tal proporção foi considerada igual a $60 \% 13$, com erro máximo em valor absoluto de 5\% e com nível de confiança de $95 \%$. Para se obter a estimativa final do tamanho da amostra, esse valor foi ajustado usando-se um fator de correção para população finita. Ainda, considerando a possibilidade de perdas, foram acrescidos $30 \%$ para que não houvesse redução do tamanho da amostra.

Foram entrevistados 406 adolescentes entre 15 e 19 anos de idade, por meio de um formulário estruturado e pré-codificado, entre junho e dezembro de 2002 (houve 29 perdas). As entrevistas foram realizadas, majoritariamente, no próprio domicílio dos adolescentes selecionados. É preciso salientar que a entrevista foi conduzida respeitando-se a privacidade do jovem e, mesmo tendo sido planejada para ser conduzida no domicílio do adolescente, foi dada a opção para que ele escolhesse o local em que se sentisse mais confortável para responder às perguntas, como, por exemplo, um cômodo específico de sua casa, quintal, casa de vizinhos/parentes, espaço público, centro de juventude e outros. Além disso, foram oferecidos, aos entrevistados, preservativos masculinos, panfletos educativos sobre prevenção de doenças sexualmente transmissíveis/AIDS e uma listagem com os serviços disponíveis na cidade de São Paulo para mulheres vítimas de violência.

Para dar conta do número de entrevistas que deveriam ser realizadas, formou-se uma equipe com duas entrevistadoras, além da pesquisadora responsável (que realizou mais da metade das entrevistas). As duas entrevistadoras foram treinadas para a aplicação do instrumento e para a abordagem do adolescente, sendo acompanhadas semanalmente com muita atenção. Todos os instrumentos preenchidos foram revisados em conjunto com a entrevistadora e, posteriormente, foram anotadas as respostas pré-codificadas na coluna para digitação do banco de dados.

A confiabilidade dos dados coletados pelas duas entrevistadoras foi checada tanto por meio da comparação dos dados sócio-demográficos dos adolescentes com as informações contidas na ficha de cadastro do SIAB, quanto por meio de uma visita domiciliar posterior à entrevista para a confirmação dos dados preenchidos em mais da metade das entrevistas.

O instrumento foi preenchido com muita facilidade e, na maior parte das vezes, com rapidez (cerca de 15 a 20 minutos). A ordem em que foram colocadas as questões, iniciando com perguntas sobre as informações mais gerais sobre os adolescentes e sua família e finalizando com as perguntas relacionadas à sua sexualidade, portanto, mais íntimas e que poderiam trazer algum embaraço aos adolescentes, possibilitou o estabelecimento de um ambiente de tranqüilidade $\mathrm{e}$ confiança durante a entrevista. Todas as questões com alternativas foram pré-codificadas, bastando que a entrevistadora circulasse o item correto. Do lado direito de cada pergunta, havia o nome da variável conforme sua entrada no banco de dados, entretanto, a resposta final, nessa coluna, somente foi marcada pela pesquisadora responsável, após análise e discussão dos questionários com cada entrevistador e checagem da fidedignidade dos dados ali apresentados.

Entre os entrevistados, 222 (54,7\%) eram do sexo feminino, e 184 (45,3\%), do sexo masculino. Por conta dos objetivos do presente estudo, que consistem em conhecer a trajetória afetivo-amorosa de adolescentes do sexo masculino e razões para o início ou adiamento da vida sexual, os dados apresentados são concernentes apenas aos 184 homens entrevistados.

A apresentação dos resultados foi dividida em três partes:

a) Dados de todos os adolescentes e de suas primeiras parcerias segundo as variáveis "primeiro beijo" (idade média e proporção), "primeiro namoro" (idade média e proporção), "primeira relação sexual” (idade média e proporção). Não 
houve qualquer tipo de dificuldade entre os entrevistados em relação ao que seria primeiro beijo, primeiro namoro ou primeira relação sexual. Mesmo assim, essa última foi enfatizada como sendo sexo com penetração vaginal ou anal.

b) Dados dos adolescentes que já tiveram alguma relação sexual segundo a variável "razão para o engajamento na vida sexual". A pergunta permitia apenas uma resposta e era estimulada por meio das alternativas curiosidade, atração, amor, pressão da(o) parceira(o) e queria perder a virgindade. As alternativas pressão dos amigos e outra razão não foram referidas por nenhum adolescente.

c) Dados dos adolescentes que nunca tiveram uma relação sexual segundo a variável "razão para o não engajamento em atividade sexual". As alternativas preestabelecidas foram ainda não encontrou a pessoa certa, quer se casar virgem, não teve oportunidade, tem medo de engravidar e tem medo de DST/AIDS - as duas últimas agrupadas em uma só - além de ainda é muito novo. Nenhum adolescente relatou outra razão. Outra variável analisada foi o "momento considerado mais adequado para ter a primeira relação sexual", cujas alternativas preestabelecidas foram quando se casar, quando for noivo, quando tiver namorada(o) - as duas últimas agrupadas em uma só - assim que possível, quando for mais maduro, quando gostar de alguém. As alternativas quando tiver determinada idade e quando terminar os estudos não foram apontadas por nenhum adolescente. Cabe ressaltar que nenhum adolescente recusou a responder tais questões nem apontaram a alternativa não sei.

Ressalte-se que não há informação a respeito do sexo da primeira parceria nos eventos pesquisados.

Os dados foram descritos por meio de proporções e medidas de tendência central. A análise das variáveis associadas à idade foi realizada por meio do teste de associação pelo qui-quadrado, e a análise das diferenças entre os valores médios foi realizada por meio do teste de MannWhitney.

Este estudo adotou procedimentos que garantiram a não-discriminação ou estigmatização dos indivíduos envolvidos na pesquisa. Os jovens foram convidados a participar do estudo após uma explicação de seus objetivos, do conteúdo de suas questões e da instituição em que era desenvolvido. Foi enfatizado que as perguntas eram de cunho íntimo e que eles poderiam recusar-se a dar continuidade à entrevista a qualquer momento. Também foi assegurado que a identidade deles seria mantida em sigilo. Foram garantidos a privacidade, confidencialidade e anonimato e respeitados os valores sócio-culturais. Os con- sentimentos foram obtidos com os responsáveis pelo adolescente ou com ele próprio, desde que com idade igual ou superior a 18 anos. Esta pesquisa foi aprovada pela Comissão de Ética e Pesquisa da Faculdade de Saúde Pública, Universidade de São Paulo.

\section{Caracterização dos entrevistados}

A caracterização dos adolescentes homens revela que tinham 16,8 anos de idade em média $(\mathrm{DP}=1,3$ ) e mediana de 17,0 anos. A maior parte era estudante $(77,2 \%$ ou 142$)$. Entre esses, $20,4 \%$ (29) também estavam trabalhando. A ausência de inserção escolar simultaneamente à ausência de inserção no mercado de trabalho atingiu 21 adolescentes (11,4\%). Muitos moravam em casas próprias $(63 \%)$ ou de aluguel $(10,9 \%)$, porém $26,1 \%$ relataram morar em habitações ocupadas. Seus domicílios possuíam, em média, 4,8 cômodos (DP $=1,8)$ e 5,2 moradores. Os adolescentes classificaram-se como de cor parda (44\%) e preta $(23,4 \%)$, ao passo que $32,6 \%$ referiram ser de cor branca. Nenhum adolescente relatou a cor amarela ou indígena.

A maior parte dos adolescentes nasceu na Região Metropolitana de São Paulo (79,9\%), apesar de uma considerável proporção de seus pais e mães $(69,5 \%$ e $68 \%$ respectivamente) ter nascido em outras regiões do país, principalmente o Nordeste, e migrado para a cidade de São Paulo. Em relação ao estado conjugal, 97,8\% (180) dos adolescentes disseram ser solteiros, dois estavam unidos e dois encontravam-se separados no momento da entrevista. A caracterização revelou, pois, que são indivíduos inseridos em contextos de precária inserção social, com perfil típico de jovens moradores de áreas periféricas de grandes cidades brasileiras.

\section{Resultados}

O primeiro beijo foi dado aos 11,5 anos de idade, com pessoas que tinham 11,9 anos de idade (valores médios). O primeiro namoro ocorreu aos 13,2 anos de idade com indivíduos que tinham 13,3 anos de idade (em média). A primeira relação sexual ocorreu aos 14,9 anos com parceiras(os) que tinham 16,4 anos de idade (valores médios - resultados mostrados na Tabela 1). Entre os unidos, os resultados mostraram que sua primeira união ocorreu aos 17,5 anos de idade com pessoas de 16,0 anos de idade, ambos os valores médios (Tabela 1).

Alguns adolescentes $(5,4 \%)$ nunca haviam beijado até o momento em que a entrevista foi 
Valores médios, desvios padrão, medianas, valores máximos e mínimos das idades no primeiro beijo, primeiro namoro, primeira relação sexual e primeira união, seguidos das respectivas parcerias. São Paulo, Brasil, 2002.

\begin{tabular}{|c|c|c|c|c|}
\hline Valores & $\begin{array}{c}\text { 1o beijo } \\
(N=174)\end{array}$ & $\begin{array}{l}\text { 1ㅇ namoro } \\
(\mathrm{N}=163)\end{array}$ & $\begin{array}{c}\text { 1ạ relação } \\
(\mathrm{N}=86)\end{array}$ & $\begin{array}{c}\text { 1ạ união } \\
(\mathrm{N}=4)\end{array}$ \\
\hline \multicolumn{5}{|l|}{ Adolescentes } \\
\hline Média & 11,5 & 13,2 & 14,9 & 17,5 \\
\hline Desvio padrão & 2,2 & 2,1 & 1,5 & 0,6 \\
\hline Mediana & 12,0 & 13,0 & 15,0 & 17,5 \\
\hline Valor mínimo-máximo & $7,0-18,0$ & $7,0-18,0$ & $8,0-18,0$ & $17,0-18,0$ \\
\hline \multicolumn{5}{|l|}{ Parceiras(os) } \\
\hline Média & 11,9 & 13,3 & 16,4 & 16,0 \\
\hline Desvio padrão & 2,2 & 2,2 & 3,1 & 0,8 \\
\hline Mediana & 12,0 & 13,0 & 16,0 & 16,0 \\
\hline Valor mínimo-máximo & $6,0-18,0$ & $7,0-22,0$ & $8,0-28,0$ & $15,0-17,0$ \\
\hline
\end{tabular}

realizada. Cabe ressaltar que, entre todos os entrevistados, $11,4 \%$ ainda não tinham vivenciado uma relação de namoro, e 53,3\% não haviam iniciado sua vida sexual. A idade foi associada estatisticamente ao início da vida sexual $(\mathrm{p}<0,0001)$, resultado mostrado na Tabela 2 . Os adolescentes virgens eram um ano mais novos que os sexualmente experientes $(16,3 \pm 1,3$ e 17,3 $\pm 1,3$ anos, respectivamente).

Os adolescentes que já haviam iniciado a vida sexual referiram, em maior parte, a atração pela(o) primeira(o) parceira(o) sexual como a principal motivação para iniciação sexual $(54,7 \%)$, conforme Figura 1.

Ao todo, 98 adolescentes não haviam tido nenhuma relação sexual. Um pouco mais da metade revelou que ainda não havia encontrado a pessoa certa para a iniciação sexual $(53,2 \%)$ e, por isso, permanecia virgem. Outras razões relatadas são mostradas na Figura 2.

Quando questionados sobre o momento mais provável em que teriam a primeira relação sexual, a maior parte referiu que aguardaria o envolvimento em um relacionamento afetivo-amoroso, como namoro ou noivado $(31,6 \%)$ e casamento (20,4\%). Uma outra parte destacou que gostaria de esperar ter mais maturidade ao passo que alguns gostariam de esperar por alguém por quem nutrissem um sentimento de amor. Onze garotos $(11,2 \%)$ revelaram o desejo imediato de iniciação sexual e iriam aproveitar a primeira oportunidade que surgisse. Tais dados também são mostrados na Figura 2.

Cabe enfatizar que não houve diferença estatisticamente significativa nas idades médias entre os adolescentes no tocante a suas razões para o não engajamento sexual ou à sua opinião sobre o momento mais adequado para tal evento.

\section{Discussão}

Os eventos beijo e namoro mostraram-se quase universais na população de estudo, provavelmente porque tendem a ocorrer nos primeiros anos da adolescência, ou seja, antes do período compreendido entre os 15 e 19 anos de idade, no qual os adolescentes entrevistados estão incluídos. Esse fato parece sugerir que as primeiras manifestações afetivo-amorosas e, provavelmente, as primeiras experiências pré-sexuais, que normalmente estão presentes em relacionamentos de namoro, ocorrem predominantemente antes dos 15 anos de idade. A importância do evento ficar é traduzida pelo intervalo de tempo entre o primeiro beijo e o primeiro namoro $(1,6$ ano), revelando que é um tipo de relacionamento que não pressupõe compromisso entre as partes, mas, afirmou Rieth 10 , faz parte do roteiro de experimentação sexual dos adolescentes.

Note-se que há uma certa convergência da idade dos homens em relação às suas primeiras parcerias no tocante aos beijos e namoros, contrariamente ao que ocorre com as mulheres, em que seus parceiros são geralmente mais velhos, conforme observaram Borges \& Schor 14 .

A primeira relação sexual foi relatada por menos da metade dos garotos entre 15 e 19 anos de idade e observou-se que tal evento vai ganhando maior dimensão ao longo da adolescência, principalmente após os 16 anos de idade, quando foi observado um salto em sua proporção em comparação aos 17 anos de idade. Faz-se necessário, a partir do conhecimento da idade mais freqüente de iniciação sexual, estabelecer um esforço para que as ações de promoção da saúde do adolescente que tenham como enfoque a saúde reprodutiva e sexual alcance-os antes de seu 
Tabela 2

Distribuição dos adolescentes por idade segundo beijo anterior, namoro anterior e início da vida sexual. São Paulo, Brasil, 2002.

\begin{tabular}{|c|c|c|c|c|c|c|}
\hline \multirow[b]{2}{*}{ Variável } & \multicolumn{6}{|c|}{ Idade (anos) } \\
\hline & 15 & 16 & 17 & 18 & 19 & Total \\
\hline \multicolumn{7}{|c|}{ Beijo anterior $(n=184)$} \\
\hline Não & $4(9,1)$ & $1(2,4)$ & $1(2,4)$ & $2(6,7)$ & $2(7,7)$ & $10(5,4)$ \\
\hline Sim & $40(90,9)$ & $41(97,6)$ & $41(97,6)$ & $28(93,3)$ & $24(92,3)$ & $174(94,6)$ \\
\hline \multicolumn{7}{|c|}{ Namoro anterior $(n=184)$} \\
\hline Não & $10(22,7)$ & $3(7,1)$ & $4(9,5)$ & $2(6,7)$ & $2(7,7)$ & $21(11,4)$ \\
\hline Sim & $34(77,3)$ & $39(92,9)$ & $38(90,5)$ & $28(93,3)$ & $24(92,3)$ & $163(88,6)$ \\
\hline \multicolumn{7}{|c|}{ Início da vida sexual $(n=184)$ * } \\
\hline Não & $35(79,5)$ & $30(71,4)$ & $15(35,7)$ & $9(30,0)$ & $9(34,6)$ & $98(53,3)$ \\
\hline Sim & $9(20,5)$ & $12(28,6)$ & $27(64,3)$ & $21(70,0)$ & $17(65,4)$ & $86(46,7)$ \\
\hline
\end{tabular}

Os valores entre parênteses são proporções.

${ }^{*} p<0,0001$.

Figura 1

Razões de iniciação sexual segundo adolescentes com experiência sexual. São Paulo, Brasil, 2002.

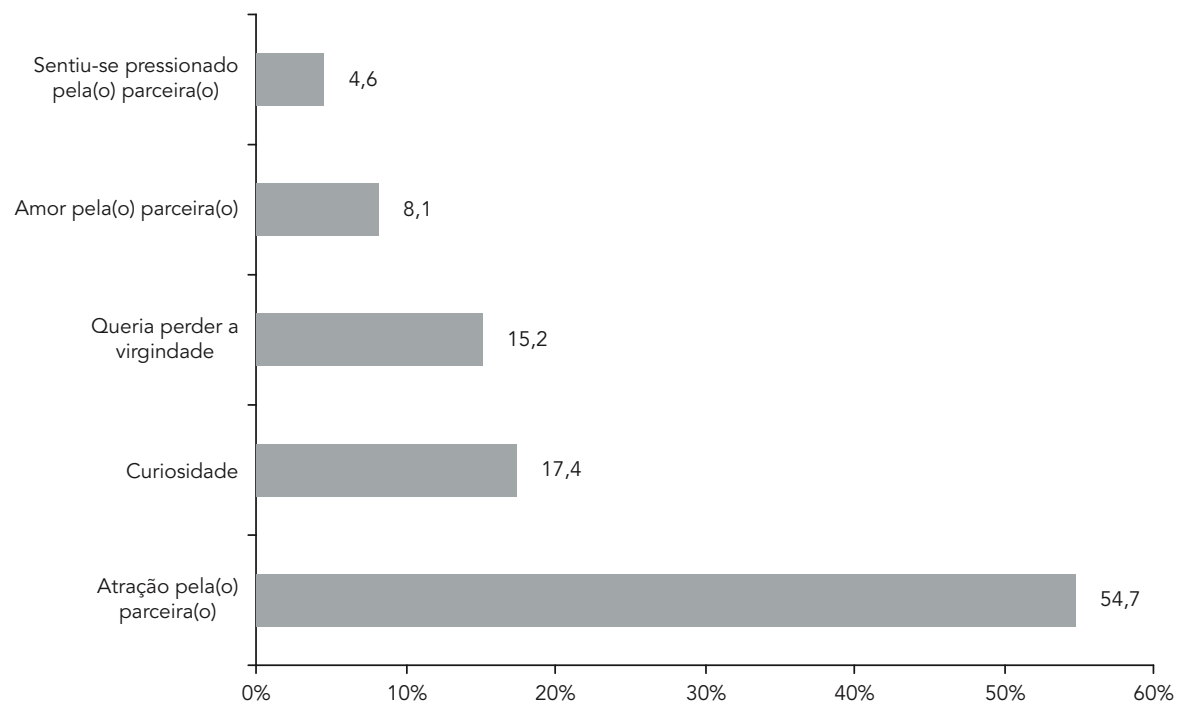

engajamento sexual, no intuito de criar atitudes favoráveis que diminuam os riscos do sexo não protegido e promovam um início da vida sexual mais saudável.

No contexto de iniciação sexual, as primeiras parcerias mostraram-se relativamente mais velhas (quase 1,5 ano). Esse aspecto já foi observado por Olavarría 15, a partir de seu estudo com homens chilenos heterossexuais, em que alguns entrevistados relataram a iniciação sexual com mulheres mais velhas e, muitas vezes, também já experientes sexualmente, inserindo-os em uma relação em que a iniciativa foi da mulher e não mais deles. $\mathrm{O}$ autor salientou que a atitude ativa das mulheres seria especialmente válida na situação de iniciação sexual, embora, de certa forma, pudesse causar certa sensação de desconcerto para aqueles homens. 
Distribuição dos adolescentes sem experiência sexual segundo as razões apontadas para não ter iniciado a vida sexual e o momento considerado mais adequado para a iniciação sexual. São Paulo, Brasil, 2002.

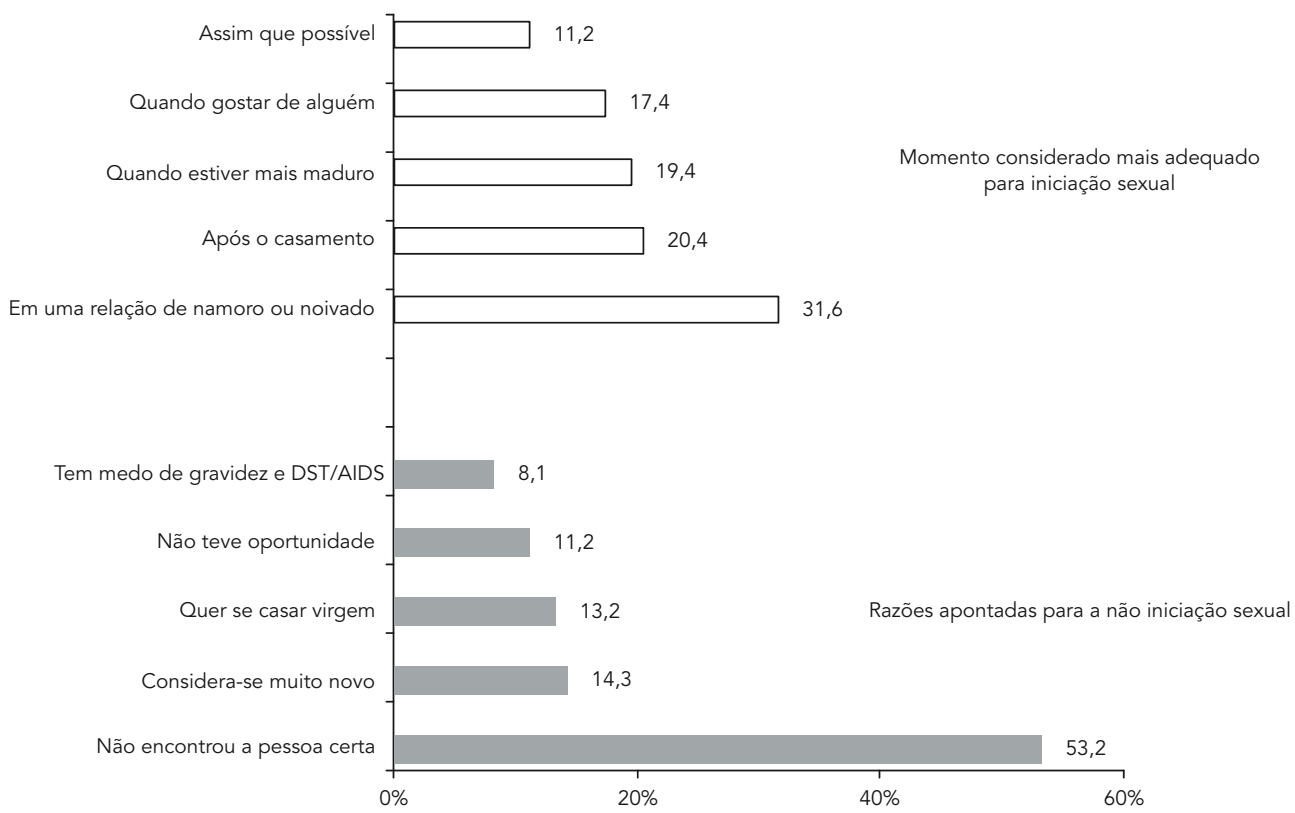

Um pouco mais da metade dos adolescentes com experiência sexual prévia relatou que sua principal motivação para a iniciação sexual foi a atração pela(o) primeira(o) parceira(o). Aqui faz sentido a idéia que o objeto de desejo desses homens seria de ordem física, e, assim, o primeiro ato sexual compreenderia uma forma de satisfação do instinto e da necessidade de dar vazão à atração.

Para outros tantos, a curiosidade foi o mote para a iniciação sexual tanto quanto o desejo de não ser mais virgem, revelando um caráter maior de experimentação. Pelos relatos, pode-se concluir também que há, muito possivelmente, um código de conduta prescrevendo que, em determinado momento ou a partir de uma certa idade, a virgindade passa a ser um peso na vida dos adolescentes, servindo também como elemento de pressão para que haja a iniciação sexual. Ou seja, alguns adolescentes iniciaram a vida sexual claramente porque se sentiram pressionados pelas(os) suas(seus) parceiras(os) - 4,6\% - mas outra parte considerável pode ter sido estimulada a iniciar sua vida sexual sob uma outra forma de pressão, sutil e, muitas vezes, inquestionável, em razão da difusão de um modelo de comportamento sexual ditado, entre outros, pelos pares que, por sua vez, também estão sujeitos às normas sociais que modelam condutas sexuais 16,17.

Nesse sentido, Heilborn 16 acrescentou que a iniciação sexual dos garotos serve também como modo de expressão do processo de tornar-se homem, de consolidação da masculinidade, o que só pode ser alcançado entre os pares. Portanto, "ter a primeira experiência sexual não é garantia automática de um novo status. É necessário o reconhecimento dos pares, que confere legitimidade à passagem" 16 (p. 401).

Ainda a respeito de normas e padrões sociais de iniciação sexual, a partir do relato de homens chilenos heterossexuais que já viviam com suas companheiras ou esposas, foi discutido que a convivência entre os pares seria o "lugar" mais importante em relação à socialização da sexualidade 15. Segundo o autor 15 (p. 162), “aquilo que não pôde ser conversado e aprendido em casa ou no colégio seria encontrado entre os iguais. Esse espaço permitiria incorporar novas interpretações sobre o corpo e o desejo elou reafirmar as aprendidas. Aqui se incorporariam padrões e sentidos 
subjetivos. É o espaço em que se observam os adultos e se aprendem seus comportamentos, é onde se iniciam as competições entre os homens".

A baixa proporção de adolescentes que indicou ter iniciado sua vida sexual por amor ratifica que o amor e o sexo seriam, para esses homens, experiências que correspondem a espaços distintos 15 , ao contrário do que identificou Borges 3 nas mulheres adolescentes, em que o amor foi a motivação mais referida para a iniciação sexual. Em concordância com esse dado, Moreira \& Juarez 18 relataram que $71,1 \%$ dos mais de mil adolescentes de ambos os sexos entrevistados em uma comunidade de baixa renda da cidade de Recife, Pernambuco, Brasil, identificaram o envolvimento sexual como necessidade mais comum ao homem do que à mulher, o que sugere ainda haver um modelo hegemônico de masculinidade, ao qual os homens sofrem pressões sociais para endossar 19 .

Em relação aos adolescentes que nunca haviam tido qualquer relação sexual (53,3\%), saliente-se que a maior parte justificou sua opção pela virgindade por conta de razões de ordem amorosa, como o fato de não ter encontrado a pessoa certa ou porque queria manter-se virgem até o casamento, totalizando $66,4 \%$. A ênfase do aspecto afetivo-amoroso na iniciação sexual atribuída pelos homens virgens foi ratificada pelas respostas dos adolescentes no tocante ao momento considerado mais adequado para a sua iniciação sexual. O caráter romântico emergiu mais uma vez, tendo em vista que $69,4 \%$ dos entrevistados relataram um contexto de relacionamento com envolvimento de sentimentos de paixão e amor como ideal para iniciar-se sexualmente, tendo como pano de fundo o namoro, o noivado, o casamento ou o momento em que gostasse de alguém. Praticamente um, em cada cinco homens sem experiência sexual, elegeu o casamento como o contexto ideal da iniciação sexual.

Rieth 10 também verificou, entre seus entrevistados gaúchos vivendo na fase da adolescência, que alguns se assumiram decididamente românticos, conjugando sexo com sentimentos de amor, e, dessa forma, a virgindade seria uma alternativa para atingir essa interação (sexo e amor), aproximando-se de um comportamento de "entrega" ao ser amado mais próximo da perspectiva dita feminina. Para essa autora 10 (p. 131), os arranjos de amor e sexo "apresentam uma coexistência do tradicional e do moderno, regendo as relações de gênero e conformando os múltiplos processos de individuação".

Cabe enfatizar que uma comparação entre os argumentos dos adolescentes "com" e "sem" experiência sexual faz emanar um certo contra- ponto entre ambos, sugerindo um duplo padrão social no âmbito da primeira experiência sexual, em que há a valorização do sentimento de amor e entrega à pessoa amada ao mesmo tempo em que se advoga a premência física e instintiva assim como uma intencionalidade ativa e ininterrupta para o sexo, baseado também nos relatos de que pretende engajar-se sexualmente "assim que possível".

Pode ser que a diferença na idade entre os adolescentes virgens e não virgens incida sobre suas aspirações e valores, já que os primeiros são um ano mais jovens, em média. Mesmo assim, tais resultados parecem ser inovadores no sentido de apontar comportamentos diferenciados entre os homens adolescentes, contrariamente ao relato 20 de que os repertórios usados para a construção da cultura sexual dos rapazes sofreram um impacto muito pequeno, mantendo vigentes concepções associadas ao poder de conquista e da performance.

Pelos relatos dos adolescentes entrevistados, verifica-se que isso não é verdade absoluta para o conjunto dos homens adolescentes, mas apenas para uma parte deles. Aparentemente, vários garotos baseiam-se nos sentimentos amorosos para decidirem sobre a iniciação sexual, e esse ponto de vista deve ser reconhecido, respeitado e considerado pelos profissionais que assistem a esses adolescentes no sentido de não reduzir seu comportamento sexual a mero desejo físico, instintivo e incontrolável. De acordo com Schraiber et al. 19 (p. 33), " a saúde coletiva atua com homens concretos que podem se aproximar ou se distanciar dos modelos presentes na cultura. Saber trabalhar com a pluralidade de modelos, a reinvenção deles e com as singularidades, sem dúvida éo desafio para se abordar a saúde do homem".

Os resultados confirmaram que os homens necessitam ser vistos em sua singularidade e diversidade, mas também no âmbito de suas relações com o outro, seja a parceria afetivo-sexual, seja seu grupo de iguais, assim como com sua rede de inserção sócio-cultural 21, visto que sofrem pressões sociais para ratificar modelos de uma certa masculinidade dominante. Ainda, padrões tradicionais de masculinidade, como a dissociação entre sexo e amor, parecem estar sendo transpostos no tocante à iniciação sexual, momento em que os homens adolescentes buscam viver modelos de sexualidade com base em diversos outros referenciais além do tradicionalmente imbuído à masculinidade, contemplando, muitas vezes, as questões do amor, romance e compromisso nos primeiros relacionamentos sexuais.

Os profissionais de saúde devem estar preparados, pois, para a diversidade dos modos de 
viver a adolescência e de viver a sexualidade na adolescência, bem como o impacto que tais decisões podem ocasionar na saúde sexual e reprodutiva dos homens adolescentes e suas primeiras parcerias sexuais. Além disso, deve-se ter em vista que a compreensão dos aspectos que cercam o comportamento sexual de homens adolescentes possibilita também uma maior compreensão da sua conseqüência para as mulheres, para a vida em parceria e para alcançar uma maior eqüidade de gênero 15,22 .

\section{Resumo}

Buscou-se descrever a trajetória afetivo-amorosa e razões para o início ou adiamento da vida sexual de adolescentes do sexo masculino, por meio de entrevistas com 184 homens de 15 a 19 anos de idade, residentes no Município de São Paulo, Brasil, em 2002. O início da vida sexual ocorreu, entre outros, por conta da atração física, da curiosidade e do desejo de perder a virgindade, sugerindo um caráter mais próximo do papel social masculino. Por outro lado, a maior parte dos adolescentes virgens justificou sua opção por questões de ordem romântica, como não ter encontrado a pessoa certa ou porque gostaria de casar-se virgem. Os resultados revelaram um duplo padrão social em que há a valorização do sentimento de amor e entrega à pessoa amada simultaneamente à premência física e instintiva para o sexo. Padrões tradicionais de masculinidade, como a dissociação entre sexo e amor, parecem estar sendo transpostos no tocante à iniciação sexual, revelando diversidade nos modos de viver a sexualidade na adolescência que, por sua vez, estão relacionados à saúde sexual e reprodutiva dos homens e suas parcerias.

Saúde Sexual e Reprodutiva; Saúde do Adolescente; Saúde do Homem

\section{Colaboradores}

A. L. V. Borges participou da revisão de literatura, elaboração da metodologia, análise dos resultados e redação do artigo final. N. Schor participou na elaboração do artigo e revisão final. 


\section{Referências}

1. Figueroa-Perea JG. Algunos elementos para interpretar la presencia de los varones en los procesos de salud reproductiva. Cad Saúde Pública 1998; 14 Suppl 1:87-96.

2. Schor N. Adolescência e anticoncepção - conhecimento e uso [Tese de Livre-docência]. São Paulo: Faculdade de Saúde Pública, Universidade de São Paulo; 1995.

3. Borges ALV. Adolescência e vida sexual: análise do início da vida sexual de adolescentes residentes na zona leste do Município de São Paulo [Tese de Doutorado]. São Paulo: Faculdade de Saúde Pública, Universidade de São Paulo; 2005.

4. Schwartz IM. Sexual activity prior to coital initiation: a comparison between males and females. Arch Sex Behav 1999; 28:63-9.

5. Bem-Estar Familiar no Brasil. Pesquisa Nacional sobre Demografia e Saúde - 1996. Rio de Janeiro: Bem-Estar Familiar no Brasil; 1997.

6. Aquino EML, Heilborn ML, Knauth D, Bozon M, Almeida MC, Araújo J, et al. Adolescência e reprodução no Brasil: a heterogeneidade dos perfis sociais. Cad Saúde Pública 2003; 19 Suppl 2: 377-88.

7. Almeida MCC, Aquino EML, Gaffikin L, Magnani RJ. Uso de contracepção por adolescentes de escolas públicas na Bahia. Rev Saúde Pública 2003; 37:566-75.

8. Szwarcwald CL, Barbosa Júnior A, Pascom AR, Souza Júnior PR. Pesquisa de conhecimento, atitudes e práticas na população brasileira de 15 a 54 anos, 2004. Boletim Epidemiológico AIDST 2005; I:18-24.

9. Bozon M, Heilborn ML. As carícias e as palavras: iniciação sexual no Rio de Janeiro e em Paris. Novos Estudos-CEBRAP 2001; 59:111-35.

10. Rieth F. Ficar e namorar. In: Bruschini C, Hollanda HB, organizadores. Horizontes plurais: novos estudos de gênero no Brasil. São Paulo: Editora 34; 1998. p. 113-33.

11. Peres F, Rosemburg CP. Desvelando a concepção de adolescência/adolescente presente no discurso da saúde pública. Saúde Soc 1998; 7:53-86.

12. Borges ALV, Schor N. Início da vida sexual na adolescência e relações de gênero: um estudo transversal em São Paulo, Brasil, 2002. Cad Saúde Pública $2005 ; 21: 499-507$.
13. Centro Brasileiro de Análise e Planejamento, Ministério da Saúde. Pesquisa sobre comportamento sexual e percepções da população brasileira sobre HIV/AIDS. Brasília: Ministério da Saúde; 2000.

14. Borges ALV, Schor N. Trajetórias afetivo-amorosas e perfil reprodutivo de mulheres adolescentes residentes no Município de São Paulo. Rev Bras Saúde Matern Infant 2005; 5:163-70.

15. Olavarría J. Desejo, prazer e poder: questões em torno da masculinidade heterossexual. In: Barbosa RM, Parker RP, organizadores. Sexualidades pelo avesso: direitos, identidades e poder. São Paulo: Editora 34; 1999. p. 153-74.

16. Heilborn ML. A primeira vez nunca se esquece. Revista Estudos Feministas 1998; 6:394-405.

17. Kinsman SB, Romer D, Furstenberg FF, Schwarz DF. Early sexual initiation: the role of peer norms. Pediatrics 1998; 102:1185-92.

18. Moreira MM, Juarez F. Comportamento sexual de adolescentes do sexo masculino de baixa renda: a comunidade de Chão de Estrelas em Recife, Pernambuco. In: XIV Encontro Nacional de Estudos Populacionais. Campinas: Associação Brasileira de Estudos Populacionais; 2004. p. 1-17.

19. Schraiber LB, Gomes R, Couto MT. Saúde do homem: uma abordagem em construção. Ciênc Saúde Coletiva 2005; 10:32-4.

20. Arilha M, Calazans G. Sexualidade na adolescência: o que há de novo? In: Comissão Nacional de População e Desenvolvimento, organizador. Jovens acontecendo na trilha das políticas públicas. v. 1. Brasília: Comissão Nacional de População e Desenvolvimento; 1998. p. 687-709.

21. Gomes R. Sexualidade masculina e saúde do homem: proposta para uma discussão. Ciênc Saúde Coletiva 2003; 8:825-9.

22. Barker G. Homens e igualdade de gênero. In: Parker R, Corrêa S, organizadores. Sexualidade e política na América Latina. Rio de Janeiro: Associação Brasileira Interdisciplinar de AIDS; 2003. p. 71-6.

Recebido em 04/Out/2005

Versão final reapresentada em 22/Fev/2006

Aprovado em 19/Mai/2006 